\title{
Oxygen Therapy in COPD
}

\author{
Richard D Branson MSc RRT FAARC
}

\author{
Introduction \\ LTOT in COPD With Severe Hypoxemia \\ LTOT in COPD With Moderate Hypoxemia \\ LTOT for Exertional Desaturation \\ LTOT for Nocturnal Desaturation \\ Oxygen for COPD Exacerbation \\ Oxygen for Palliative Care in COPD \\ Home Oxygen Delivery Systems \\ The Oxygen Prescription \\ Oxygen Source \\ Cylinders \\ Liquid \\ Concentrators \\ Portable Oxygen Concentrators and the Meaning of Settings \\ Closed-Loop Control of Oxygen at Home \\ Oxygen Therapy and Noninvasive Ventilation \\ Summary
}

Long-term oxygen therapy (LTOT) at home has been demonstrated to improve survival in patients with COPD and severe resting hypoxemia. Support for LTOT is based on 2 landmark trials published nearly 4 decades ago. These results form the basis for reimbursement and prescription of LTOT to this day. Recent work has demonstrated no outcome benefit of LTOT in stable COPD patients with moderate desaturation at rest or during activity. Oxygen therapy during activity and exercise has been shown to alleviate symptoms and maintain arterial oxygen saturation, but not improve long-term outcomes. Oxygen therapy in COPD has a number of physiologic, functional, and biologic effects, not all of which are completely understood. Oxygen therapy in exacerbations of COPD can be both helpful and harmful. New guidance on the use of oxygen therapy during pre-hospital care has been published in the United Kingdom. Technology for LTOT represents a challenge for physicians writing prescriptions, durable medical equipment suppliers, caregivers, and patients. New technology for automated control of LTOT shows promise but is hampered by regulatory processes and cost pressures. Recent changes in government reimbursement for home oxygen therapy also present challenges. This paper will review the current evidence regarding LTOT in COPD and the impact on mortality and functional outcomes as well as reviewing technological challenges. Key words: COPD; long-term oxygen therapy; oxygen concentrator; oxygen; quality of life. [Respir Care 2018;63(6):734-748. (C) 2018 Daedalus Enterprises] 


\section{OXYGEN THERAPY IN COPD}

\section{Introduction}

Long-term oxygen therapy (LTOT) is a common pharmacologic treatment for COPD. Estimates from government records suggest that more than one million Medicare recipients receive oxygen at home. Medicare costs for this therapy exceed $\$ 2$ billion dollars/year in the United States. ${ }^{1,2}$ The evidence base for LTOT in COPD is nearly 4 decades old, and data from these initial trials are still used as a basis for prescription and treatment. ${ }^{3,4}$ More recent trials are plagued by small numbers and physiologic end points, not outcomes. The use of oxygen in stable COPD with periodic hypoxemia associated with activity has provided the necessary data in defining the role of oxygen in this population. ${ }^{5}$ The role of oxygen in COPD exacerbation has the ability to be therapeutic and toxic. Important data, primarily from the United Kingdom, have shed important light on this issue. ${ }^{6}$ Technology for oxygen therapy can be confusing for physicians, caregivers, providers, and patients. New technology for LTOT might prove beneficial, but cost constraints and reimbursement have limited innovation.

This paper will review the large trials in support of LTOT in COPD with hypoxemia at rest as well as data from new trials, discuss the physiologic impact of oxygen therapy, evaluate LTOT in exertional hypoxemia, and discuss oxygen use during COPD exacerbation and technological issues related to home oxygen therapy. Emphasis will be placed on new data since the last comprehensive review on this subject by Criner. ${ }^{7}$

\section{LTOT in COPD With Severe Hypoxemia}

LTOT in COPD patients with resting hypoxemia, defined at $\mathrm{P}_{\mathrm{aO}_{2}}<55 \mathrm{~mm} \mathrm{Hg}$ or $<59 \mathrm{~mm} \mathrm{Hg}$ with evidence of right heart strain or polycythemia, improves survival. Two classic trials from the 1970s, the Nocturnal Oxygen Treatment Trial (NOTT) ${ }^{3}$ and the Medical Research Council (MRC) Trial, ${ }^{4}$ form the basis for LTOT. The current qualifications for LTOT used by Medicare are based on

Mr Branson is affiliated with the Division of Trauma and Critical Care, University of Cincinnati, Cincinnati, Ohio. He is also Editor in Chief of RESPIRATORY CARE.

Mr Branson presented a version of this paper at the 56th RESPIRATORY CARE Journal Conference, Respiratory Medications for COPD and Adult Asthma: Pharmacologic Actions to Clinical Applications, held June 2223, 2017 in St Petersburg, Florida.

Correspondence: Richard D Branson MSc RRT FAARC, Division of Trauma and Critical Care, University of Cincinnati, 231 Albert Sabin Way \#558, Cincinnati, OH 45267. E-mail: Richard.branson@uc.edu.

DOI: $10.4187 /$ respcare.06312 these studies. Table 1 provides the current recommendations for continuous delivery of home oxygen.

The NOTT enrolled 203 subjects with COPD and hypoxemia at rest. Subjects were randomized to receive either continuous oxygen therapy or $12 \mathrm{~h}$ of nocturnal oxygen therapy. The primary outcome at 12 months was mortality. Additionally, pulmonary vascular pressures, neuropsychological function, and quality of life were determined at 12 months. Mean survival for the entire cohort was a mean of 19.3 months. At the 1-year follow-up, mortality was $11.9 \%$ in the continuous oxygen therapy group and $20.6 \%$ in the nocturnal oxygen therapy group. At 24 months, the mortality was $22.4 \%$ in the continuous oxygen therapy group and $40.8 \%$ in the nocturnal oxygen therapy group, nearly a 2 -fold difference. The continuous oxygen therapy cohort had a greater reduction in hematocrit and pulmonary vascular resistance at 12 months. Other outcomes measures, including $\mathrm{FEV}_{1}$, lung volumes, gas exchange, and lung volumes, were not different between groups. ${ }^{3} \mathrm{~A}$ lack of change in lung function indices is consistent with the progressive, irreversible nature of COPD.

The MRC trial ${ }^{4}$ was performed in the United Kingdom and enrolled 87 subjects with chronic bronchitis or emphysema with severe hypoxemia at rest and carbon dioxide retention. All subjects had irreversible air-flow obstruction, determined by $\mathrm{FEV}_{1}$ and evidence of elevated pulmonary artery pressures (cor pulmonale). Subjects were randomized to either no supplemental oxygen (control group) or $2 \mathrm{~L} / \mathrm{min}$ of nasal oxygen for at least $15 \mathrm{~h} / \mathrm{d}$. Mortality rate was $67 \%$ (30 of 45) in the control group and $45 \%$ (19 of 42) in the oxygen therapy group after 5 years. Mortality was associated with elevated hematocrit and elevated baseline $\mathrm{P}_{\mathrm{aCO}}$. Additionally, subjects in the oxygen therapy group had slower deterioration in gas exchange and pulmonary vascular pressures.

Although these studies are commonly considered together, there are important differences in the inclusion/exclusion, treatment, and follow-up measures. Subjects in the MRC study had a greater severity of illness along with hypercarbia and/or cor pulmonale. Subjects in the MRC study were also more likely to continue to smoke during the trial. In some respects, the treatment group in the MRC trial (12 $\mathrm{h}$ of oxygen/d) was similar to the nocturnal oxygen group in the NOTT trial. Table 2 compares the 2 trials and highlights differences in therapy and outcomes.

Taken together, the NOTT and MRC trials demonstrate that the dose of oxygen is important. Both the nocturnal oxygen treatment group from NOTT and the treatment group in MRC had a shorter duration of oxygen exposure compared with the continuous oxygen group in NOTT. Importantly, only the patients receiving continuous oxygen therapy demonstrated decreases in hematocrit and pulmonary vascular resistance. Comparing the control group of MRC (no oxygen) with the continuous oxygen therapy 


\section{OXYGEN THERAPY IN COPD}

Table 1. Current Medicare Requirements to Qualify for Home Oxygen Therapy

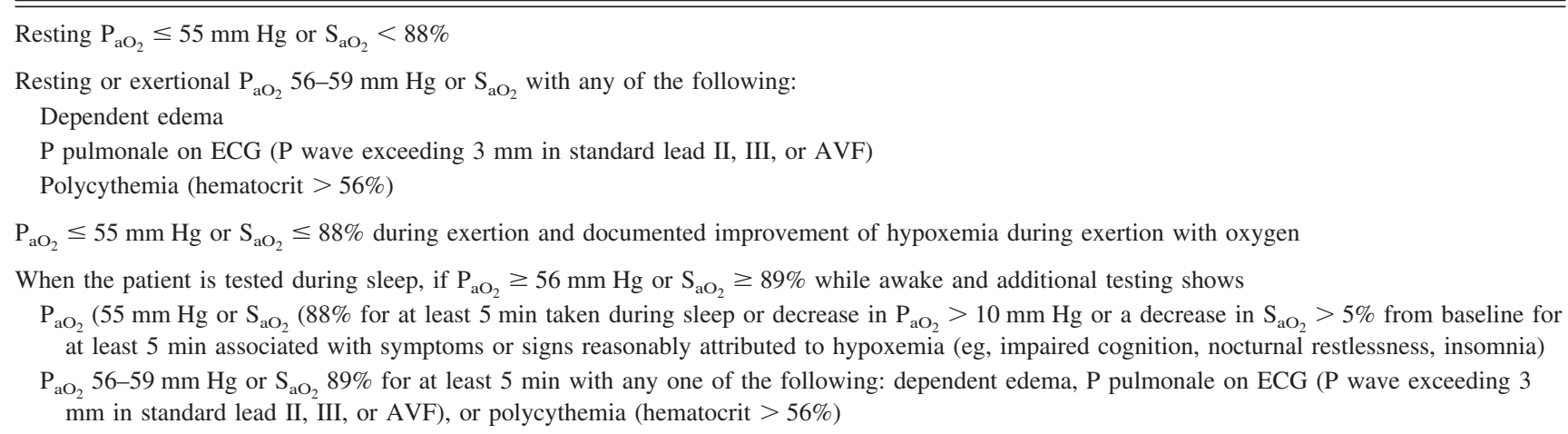

From Reference 71.

$\mathrm{ECG}=$ electrocardiogram

group of NOTT, subjects receiving oxygen had a 2-fold increase in median survival.

Further evidence for continuous LTOT comes from work in the 1980s..$^{9,10}$ Weitzenblum et $\mathrm{al}^{9}$ evaluated the impact of continuous oxygen therapy on pulmonary hemodynamics in COPD subjects with resting hypoxemia. They performed 3 right heart catheterizations in 16 subjects at baseline (mean 47 months before start of LTOT), just before the start of LTOT and after an average of 31 months of LTOT. Oxygen was prescribed for 15-18 h/d. They demonstrated that from baseline to the initiation of LTOT, there was a worsening of oxygenation and a rise in pulmonary artery pressures. Following LTOT, pulmonary artery pressures fell as a consequence of a decrease in pul- monary vascular resistance. Without oxygen, pulmonary pressures increased by $1.5 \mathrm{~mm} \mathrm{Hg} / \mathrm{y}$, whereas during LTOT, pulmonary pressures fell by $2.1 \mathrm{~mm} \mathrm{Hg} / \mathrm{y}$. These data nicely describe the impact of oxygen therapy on the progression of pulmonary hypertension. ${ }^{9}$

A second study enrolled 90 COPD subjects and performed serial right heart catheterizations for up to 6 y (75 subjects lived 2 y; only 16 were studied at year 6). They reported that LTOT resulted in a reduction in pulmonary artery pressures over the first $2 \mathrm{y}$, followed by a return to initial values and stabilization over the ensuing $4 \mathrm{y}$. Importantly, LTOT was associated with a fall in right heart pressures, but gas exchange and air-flow obstruction continued to deteriorate. ${ }^{10}$

Table 2. Comparison of the Nocturnal Oxygen Treatment Trial and the Medical Research Council Trials

\begin{tabular}{|c|c|c|}
\hline Parameters & NOTT $1980^{3}$ & MRC $1981^{4}$ \\
\hline Age, $y$ & $>35$ & $42-69$ \\
\hline Subjects, $n$ & 203 & 87 \\
\hline Male, $\%$ & $73-80$ & 76 \\
\hline Baseline $\mathrm{FEV}_{1}$ & $29 \%$ predicted & $0.58-0.75 \mathrm{~L}$ \\
\hline Baseline $\mathrm{P}_{\mathrm{aO}}, \mathrm{mm} \mathrm{Hg}$ & 51 & $49-52$ \\
\hline Baseline $\mathrm{P}_{\mathrm{aCO}}, \mathrm{mm} \mathrm{Hg}$ & 43 & $55-60$ \\
\hline $\begin{array}{l}\text { Baseline mean pulmonary artery } \\
\text { pressure, } \mathrm{mm} \mathrm{Hg}\end{array}$ & 30 & $32-35$ \\
\hline Intervention & Nocturnal oxygen vs continuous oxygen & No oxygen vs oxygen $>15 \mathrm{~h} / \mathrm{d}$ including during sleep \\
\hline Average oxygen use per day, $\mathrm{h}$ & $12 \pm 2.5$ vs $17.7 \pm 4.8$ & 0 vs 15 \\
\hline Smoking status, $\%$ & Not reported & $25-52 \%$ \\
\hline Outcomes & $\begin{array}{l}\text { Mortality, quality of life, hemodynamics: right atrial } \\
\text { pressure, right-ventricular stroke volume index, } \\
\text { pulmonary artery pressure, pulmonary vascular } \\
\text { resistance pulmonary wedge pressure, cardiac } \\
\text { index, stroke volume index }\end{array}$ & $\begin{array}{l}\text { Mortality, } 5 \text {-y mortality ( } 19 \text { of } 42 \text { with oxygen, } 30 \\
\text { of } 45 \text { without oxygen), } \mathrm{FEV}_{1}, \mathrm{FVC}, \mathrm{P}_{\mathrm{aO}_{2}}, \mathrm{P}_{\mathrm{aCO}_{2}}\end{array}$ \\
\hline $\begin{array}{l}\text { From Reference } 8 \\
\text { NOTT }=\text { Nocturnal Oxygen Treatment Trial } \\
\text { MRC }=\text { Medical Research Council }\end{array}$ & & \\
\hline
\end{tabular}




\section{OXYGEN THERAPY IN COPD}

These data, which are the basis for the use of ambulatory oxygen at home demonstrate a reversal of hypoxemia with supplemental oxygen, improved survival, and a salutary effect on pulmonary vasculature resistance. These findings only apply to subjects with COPD and resting hypoxemia and unfortunately are dated. The impact of changes in the care of COPD patients in the last 40 years suggests that perhaps LTOT be revisited. Funding for such a project seems unlikely. At present, however, the data clearly support the use of continuous oxygen therapy over nocturnal oxygen therapy to achieve the desired benefits.

\section{LTOT in COPD With Moderate Hypoxemia}

Improvements in outcomes in severe hypoxemia have raised the question of earlier use of LTOT in moderate hypoxemia. This is a common theme in medical practice, earlier intervention of a successful therapeutic option (eg, early steroids or early high-frequency ventilation in ARDS). Two important trials have failed to demonstrate any survival impact of LTOT in moderate hypoxemia. Both of these trials applied LTOT in subjects with $\mathrm{P}_{\mathrm{aO}_{2}}>56 \mathrm{~mm} \mathrm{Hg}$ and provided oxygen for an average of $13 \mathrm{~h}$ compared with a control group not receiving oxygen. Subjects were followed for 3-7 y. ${ }^{11,12}$ Criner $^{7}$ has noted that the duration of oxygen delivery in these subjects may have been insufficient to achieve the desired goals compared with the NOTT and MRC trials.

Haidl et al $^{13}$ conducted a randomized controlled trial of $2 \mathrm{~L} / \mathrm{min}$ of oxygen versus no oxygen in a group of COPD subjects with severe lung dysfunction but normoxemia. Subjects received oxygen for $15 \mathrm{~h} / \mathrm{d}$. At 12-month followup, subjects receiving oxygen had improved exercise endurance and had reduced post-exercise dyspnea, but survival was unchanged. These findings are impacted by the small sample size $(N=28)$ and short period of observation. A meta-analysis of data from these trials demonstrated no improvement in survival in COPD subjects with moderate hypoxemia. ${ }^{14}$

These data do not support the use of LTOT in moderate hypoxemia, but this population is often prescribed home oxygen therapy. Drummond et al ${ }^{15}$ analyzed data from the National Emphysema Treatment Trial (NETT) and found that a third of patients with severe disease without resting hypoxemia received home oxygen. In addition, those subjects receiving oxygen despite normoxemia experienced a higher mortality than those who did not receive oxygen. Similar findings were reported in the COPDgene study, ${ }^{16}$ where $14 \%$ of subjects were prescribed oxygen. This study included 1,060 subjects, $92 \%$ of whom did not have resting hypoxemia. ${ }^{16}$ These findings demonstrate a disconnect between the evidence supporting LTOT and those subjects likely to be prescribed home oxygen therapy.
Despite the lack of support for LTOT in moderate hypoxemia, clinicians continued to have unanswered questions related to when to use oxygen therapy in the absence of resting hypoxemia. Specifically, did subjects with exertional desaturation or nocturnal desaturation benefit from oxygen therapy? The difference between evidence and practice was the impetus for the Long Term Oxygen Treatment Trial (LOTT). ${ }^{5}$

The LOTT trial was originally designed to enroll subjects with moderate hypoxemia $\left(\mathrm{S}_{\mathrm{pO}_{2}}=89-93 \%\right)$, but poor recruitment led to expanding inclusion criteria to subjects with moderate exercise-induced hypoxemia. Moderate exercise-induced desaturation was defined as an $\mathrm{S}_{\mathrm{pO}_{2}}<90 \%$ for $\geq 10 \mathrm{~s}$ and $\mathrm{S}_{\mathrm{pO}_{2}} \geq 80 \%$ for $\geq 5 \mathrm{~min}$ during the 6-min walk test. An additional outcome of time to first hospitalization was implemented at this time. Oxygen was titrated at baseline while subjects walked and annually for the duration of the trial. Subjects were randomized to receive either no oxygen or oxygen. Within the oxygen group, subjects with resting desaturation received continuous therapy $24 \mathrm{~h} / \mathrm{d}$, and those with exercise-induced desaturation received oxygen during exercise and at night. The primary outcome of LOTT was time to death and all-cause hospitalization. Secondary outcomes included 6-min walk distance, incidence of exacerbations, healthrelated quality of life measures, and symptom burden.

During the 6-year study, 738 subjects from 42 centers were enrolled. No differences were found between the oxygen and no oxygen groups in time to death or first hospitalization or the rates of hospitalizations or COPD exacerbations. There were also no differences in the 6-min walk distance, lung function, or health-related quality of life measures. The authors concluded that in subjects with stable COPD and resting or exercise-induced oxygen desaturation, LTOT did not provide a mortality benefit or any sustained benefits in other outcomes.

Criticisms of the LOTT trial include concerns related to both selection bias and performance bias. Selection bias may have limited subjects currently using LTOT from participating; presumably, these subjects may have already been benefiting from oxygen therapy. Performance bias may have impacted outcomes, as subjects only used oxygen for an average of $13.6 \mathrm{~h} / \mathrm{d} .{ }^{17}$ This duration of oxygen use was similar to that for the subjects using nocturnal oxygen in the NOTT study. ${ }^{3}$ The results of the LOTT trial again put the evidence and clinical practice at odds. Clearly, the response to LTOT is variable among individual patients with respect to symptom relief, beyond measures of mortality.

An accompanying editorial by Ekström ${ }^{18}$ provides a practical approach to the use of oxygen therapy in COPD patients with moderate exertional hypoxemia and dyspnea. He suggests that these patients be evaluated using a blinded exercise test while breathing either air or oxygen. If there 


\section{OXYGEN THERAPY IN COPD}

is no benefit during the test or in the next few days, then the therapy is discontinued. ${ }^{19} \mathrm{He}$ also suggests that if benefit is demonstrated, the therapy should be covered by insurance. Finally, he reiterates that LTOT should not be routinely prescribed in patients with mild or moderate hypoxemia at rest or during exercise. ${ }^{18}$

In the short time since the publication of LOTT, a number of authors have made recommendations regarding oxygen therapy in this patient group. ${ }^{20-22}$ The concept of the $n$ of 1 experiment for COPD subjects with exerciseinduced moderate hypoxemia makes sense. However, the cost of these evaluations must be considered against the fact that a short-term improvement in $\mathrm{S}_{\mathrm{pO}_{2}}$ may not result in positive changes in quality of life. Hatipoğlu and Stoller ${ }^{17}$ suggested that in the group amenable to a trial of oxygen therapy titrated during a walk test, following symptom burden after several months can help identify those who benefit.

\section{LTOT for Exertional Desaturation}

Results of the LOTT in part answer the questions related to the use of LTOT for exertional hypoxemia. ${ }^{5} \mathrm{Sim}$ ilarly, the re-evaluation of the NETT provides supporting evidence that there are no long-term outcome benefits to oxygen therapy for exertional hypoxemia. ${ }^{15}$ However, there are several papers that have advocated for oxygen therapy in this setting. ${ }^{23-26}$

McDonald et $a^{23}$ evaluated 26 subjects with severe COPD but only mild hypoxemia (mean $\mathrm{P}_{\mathrm{aO}_{2}}=69 \mathrm{~mm} \mathrm{Hg}$ ) while receiving either air or oxygen during a 6-min walk test. Subjects had used either air or oxygen during activity for 12 weeks before assessments. In this randomized, blinded trial, oxygen therapy was associated with an increase in 6-min walk distance but no difference in dyspnea or quality of life measures.

Eaton et $\mathrm{al}^{24}$ studied 41 subjects with COPD, mild hypoxemia, and significant exercise desaturation $\left(\mathrm{S}_{\mathrm{aO}_{2}} 82 \%\right)$ in a double-blind randomized trial. Subjects received air or oxygen during exertional dyspnea for 12 weeks. They reported improvements in quality of life scores and reductions in anxiety and depression in the group receiving oxygen. Two additional studies identified increased 6-min walk distance ${ }^{25}$ but no changes in quality of life measures $^{25,26}$ comparing air with oxygen in a double-blind randomized fashion.

Importantly, oxygen therapy may positively impact both dyspnea and exercise intolerance in COPD. ${ }^{27-35}$ These are short-term physiologic effects and may not predict outcomes or need for continuous oxygen therapy. Oxygen therapy may improve exercise tolerance by reducing minute ventilation and therefore air trapping, improving muscle function, by increasing oxygen delivery, reducing pulmonary artery pressures, and alleviating dyspnea. ${ }^{7}$
Answers related to the role of oxygen therapy during exercise are obfuscated by variable trial designs, different exercise training regimens, and small numbers of subjects studied. A meta-analysis of oxygen during exercise concluded that COPD patients may exercise longer and at a greater intensity with less shortness of breath when using oxygen therapy. This analysis was limited to 3 small trials and could not identify the characteristics of subjects likely to benefit from oxygen therapy. ${ }^{25}$

\section{LTOT for Nocturnal Desaturation}

Nocturnal oxygen desaturation is a common occurrence in COPD patients, occurring in just under half of all patients. ${ }^{36,37}$ Nocturnal oxygen desaturation is defined as an $\mathrm{S}_{\mathrm{pO}_{2}}<90 \%$ for $>30 \%$ of the time during nocturnal oximetry. Nocturnal oxygen delivery improves oxygenation and may limit cardiac arrhythmias and help prevent elevations in blood pressure. ${ }^{38,39}$ These observations are, however, 40 y old and probably should undergo further investigation.

The data on impact of oxygen on sleep quality are mixed. ${ }^{40,41}$ It was hypothesized that nocturnal oxygen desaturation was an etiology for progressive increases in pulmonary artery pressures and subsequent cor pulmonale. ${ }^{42,43}$ However, data regarding pulmonary artery pressures in COPD refute this initial suspicion. Despite this evidence, the Medicare guidelines for home oxygen therapy include a provision of nocturnal oxygen desaturation.

Studies directly evaluating the impact of oxygen therapy on mortality are few. ${ }^{11,44-46}$ Cumulatively, these studies demonstrate no improvement in mortality with up to 3 y of nocturnal oxygen therapy. Studies are mixed with regard to changes in pulmonary artery pressure, showing either no difference or a small decrement compared with air. The paucity of recent data from quality studies has spurred new investigation. Lacasse et $\mathrm{al}^{46}$ have proposed a double-blind placebo-controlled trial to study the role of oxygen therapy in COPD subjects with nocturnal oxygen desaturation using all cause 3-y mortality as the primary end point (ClinicalTrials.gov registration NCT01044628). The review by Owens ${ }^{47}$ covers the role of oxygen during sleep across a range of maladies in great detail and is recommended reading.

\section{Oxygen for COPD Exacerbation}

The potential consequences of high-flow oxygen in the presence of COPD were described over 50 years ago by Campbell in a seminal paper in The Lancet. ${ }^{48}$ Campbell observed that high levels of inspired oxygen resulted in hypercapnia due to respiratory depression, and although the observation was correct, the mechanism was not fully understood. Work by Milic-Emili and colleagues suggested 


\section{OXYGEN THERAPY IN COPD}

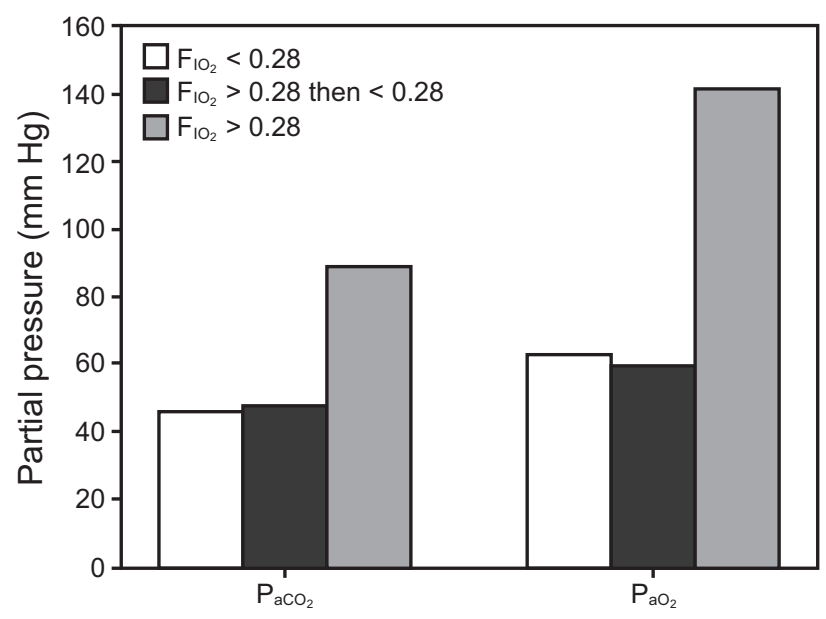

Fig. 1. Changes in $\mathrm{P}_{\mathrm{aCO}}$ and $\mathrm{P}_{\mathrm{aO}}$ during pre-hospital oxygen delivery at $\mathrm{F}_{\mathrm{IO}_{2}} \leq 0.28$, initial $\mathrm{F}_{\mathrm{IO}_{2}} \geq 0.28$ changed to $\leq 0.28$, and $\mathrm{F}_{\mathrm{IO}_{2}} \geq 0.28$. From Reference 53 .

that alterations in ventilation-perfusion matching resulting from loss of adaptive regulatory mechanisms were responsible for hypercarbia. ${ }^{49-51}$ Impressively, over half a century ago, Campbell ${ }^{48}$ suggested that patients with acute on chronic respiratory disease should receive oxygen that allows the inspired concentration to be controlled within limits of $\pm 1 \%$ over a range of $24-35 \%$.

A number of trials have evaluated the role of pre-hospital oxygen use in COPD patients. Durrington et al52 evaluated pre-hospital oxygen delivery in the United Kingdom in rural areas where transport times are commonly longer than $30 \mathrm{~min}$. They hypothesized that with prolonged transport times, the impact of excess oxygen delivery might be fully elucidated. A retrospective review of subjects admitted with COPD exacerbations was undertaken, followed by a second review after training in appropriate oxygen usage. During training, caregivers were instructed to use an air-entrainment oxygen mask at an $\mathrm{F}_{\mathrm{IO}_{2}}$ of 0.28 for initial management. Subjects in the initial phase receiving an $\mathrm{F}_{\mathrm{IO}_{2}}>0.28$ had a greater incidence of acidosis, hypercarbia, and hyperoxia (Fig. 1). Subjects receiving higher oxygen flows were more likely to have a complicated hospital course, more likely to receive aminophylline, noninvasive ventilation, and invasive ventilation. The highflow oxygen group also had a higher mortality rate.

A study of COPD exacerbations admitted to the emergency department from New Zealand showed similar outcomes. ${ }^{54}$ They found that hyperoxemia occurred in nearly a quarter of all admissions and that the number of adverse outcomes was significantly greater compared with normal oxygenation (odds ratio 9.1, 95\% CI 4.08-20.6). Hypoxemia was also associated with adverse outcomes (odds ratio $2.16,95 \%$ CI 1.11-4.20). Hyperoxia was defined as an $\mathrm{S}_{\mathrm{pO}_{2}}>96 \%$, and hypoxemia as an $\mathrm{S}_{\mathrm{pO}_{2}}$ of $<88 \%$.

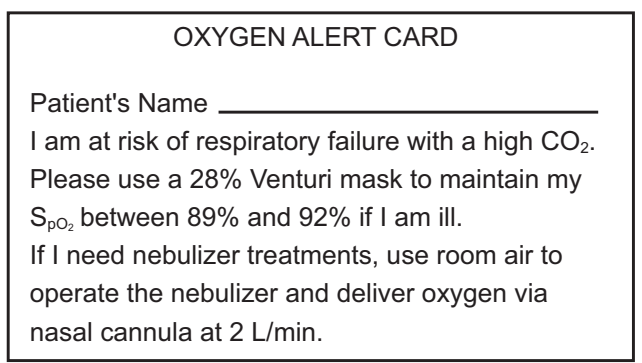

Fig. 2. Proposed example of an oxygen alert card that can be provided to patients with chronic respiratory disease at risk for hypercarbia. This includes patients with COPD as well as those with neuromuscular disease and obesity hypoventilation syndrome. From Reference 53.

These findings make a strong case for the use of titrated oxygen delivery in the patient with COPD.

Austin et al ${ }^{55}$ compared high flow $100 \%$ oxygen versus titrated oxygen treatment in a group of subjects admitted with COPD exacerbation. Mortality was 9\% (11 of 117) in the high-flow oxygen group and 2\% (2 of 97) in the titrated oxygen group. Subjects receiving high-flow oxygen were far more likely to have acidosis or hypercapnia. Other authors have made similar findings. ${ }^{56}$

The British Thoracic Society has been a leading source for change in an effort to reduce excess oxygen exposure in COPD. ${ }^{57}$ The key to success is translation of this information into emergency medical services practice. This will require specialized equipment to provide high-flow, low $\mathrm{F}_{\mathrm{IO}_{2}}$ to patients at risk. ${ }^{58,59}$ The British Thoracic Society recommendations are that each ambulance include a nonrebreathing mask for high-flow oxygen delivery, a nasal cannula or simple mask for low-flow oxygen delivery, tracheostomy masks for patients with tracheostomy or laryngectomy, and a $28 \%$ air entrainment mask. Another recommendation is that pre-hospital providers operate up-draft nebulizers for bronchodilator delivery with room air if pressurized metered-dose inhalers are unavailable. During aerosol therapy, oxygen can be provided via nasal cannula. The British Thoracic Society has also introduced cards identifying patients as having COPD and requesting use of a low $\mathrm{F}_{\mathrm{IO}_{2}}$ air entrainment mask during ambulance transport. An example of such a card is shown in Figure 2.

Changing care paradigms for COPD patients in prehospital and emergency room settings will require a fullscale educational initiative. To date, these ideas have not had widespread support. The fear of hypoxemia, rightfully so, has overshadowed the known consequences of hyperoxia in COPD. Training ambulance crews in the physiology behind carbon dioxide retention and the use of oxygen delivery devices is paramount. 


\section{OXYGEN THERAPY IN COPD}

\section{Oxygen for Palliative Care in COPD}

COPD is a progressive, irreversible disease that is primarily managed by symptom control. At the end stages of life, COPD subjects suffer from debilitating dyspnea and fear of suffocation. ${ }^{60}$

Dyspnea is profound in the last days of life, and oxygen for relief of symptoms is commonly prescribed, often at the request of families. ${ }^{61,62}$ Palliative oxygen is delivered to relieve persistent breathlessness in advanced disease or life-limiting illness. ${ }^{63}$

The common-sense approach that oxygen can relieve dyspnea is not based in fact. ${ }^{23,64-67}$ In the absence of hypoxemia, the use of oxygen to alleviate breathlessness is not supported by the literature. A randomized controlled trial of oxygen versus air in subjects at the end of life failed to show any advantage of oxygen. ${ }^{19}$ Campbell et al ${ }^{65}$ found no reduction in respiratory distress in subjects near death from respiratory failure. A meta-analysis demonstrated a positive effect of oxygen on dyspnea in COPD subjects who failed to meet the requirements for LTOT. Interestingly, dyspnea was improved by continuous-flow oxygen, but not with pulse-dose oxygen delivery. ${ }^{25}$ It is possible that oxygen delivery acts on carotid body output or another physiologic mechanism that is not fully understood. ${ }^{66}$ Davidson and Johnson ${ }^{67}$ recommend that if palliative oxygen is instituted, the success should be evaluated within $3 \mathrm{~d}$. These findings suggest that perhaps the impact of nasal oxygen flow at the end of life is secondary to washing out the upper-airway dead space versus increasing oxygenation. If this is true, high-flow nasal oxygen or air may be useful in alleviating dyspnea in palliative care. ${ }^{68}$

A recent study by Nagata et al ${ }^{69}$ compared high-flow nasal cannula (HFNC) with traditional LTOT in 32 subjects with stable hypercapnic COPD. At the end of a 12week study period, subjects receiving HFNC had improved health-related quality of life scores and a reduction in hypercapnia compared with traditional oxygen therapy. In these subjects, arterial carbon dioxide was reduced by an average of $4 \mathrm{~mm} \mathrm{Hg}$. However, there were no changes in arterial oxygenation, dyspnea, spirometry, lung volumes or 6-min walk distance. ${ }^{69}$ These results need to be replicated, and the additional cost of HFNC at home seems a challenge in the current reimbursement environment. HFNC disrupts our normal classification of oxygen therapy appliances. Traditionally there are low flow (1-6 $\mathrm{L} / \mathrm{min}$ ) and high flow devices (> 6 to $25 \mathrm{~L} / \mathrm{min}$ ). The addition of heat and humidity and a wider bore heated cirucit allows the cannula to transition to a high flow device. In this context, it is delivered oxygen (FDO2) and hyperoxia that is dangerous in COPD. High flow at low inspired oxygen concentrations, preventing hyperoxia is safe with the added benefit of washing out the deadspace and providing a low level of end expiratory pressure.
Table 3. Medicare Requirements for an Oxygen Prescription

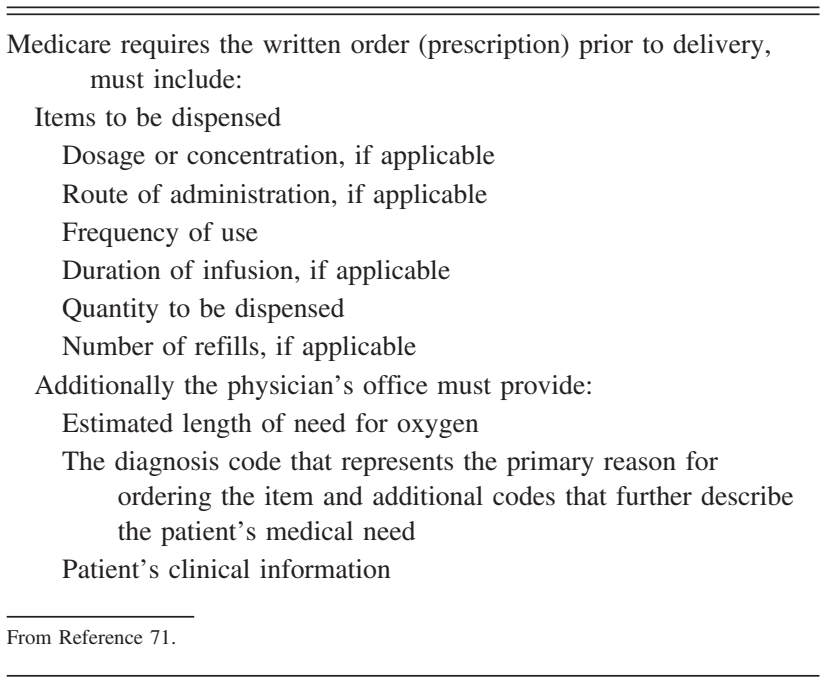

\section{Home Oxygen Delivery Systems}

Patients who qualify for LTOT have a number of options for home oxygen delivery. An extensive review of these devices was published by McCoy in $2013 . .^{70}$ The following will address issues in home oxygen therapy for LTOT.

\section{The Oxygen Prescription}

Medicare provides a 35-page document that details the requirements for reimbursable home oxygen therapy. ${ }^{71}$ This includes the written order prior to delivery. On one hand these rules are explicit and complex (Table 3). From a clinical standpoint, however, the orders fail to address issues related to maintenance of adequate oxygen saturation at all levels of activity.

Concerns regarding oxygen prescription appear to be universal, as publications from the United States, the United Kingdom, Spain, and Australia have all addressed this issue in the last 20 years..$^{72-76}$ One area of concern relates to the ability of a given oxygen therapy device provided by the supplier to meet the demands of the patient and the goals of the prescription. Complicating this problem is that home oxygen therapy reimbursement focuses on the equipment, not the care provided by a respiratory therapist familiar with the nuances of device performance. The recent Medicare change to a competitive bidding process for home oxygen therapy appears to put further cost pressures on suppliers and limits options for patients.

A successful home oxygen therapy program begins with a clear and cogent prescription for oxygen therapy that is goaloriented. The current system tends to default to the supplier which device to choose, despite unknown efficacy. A pre- 


\section{OXYGEN THERAPY IN COPD}

Table 4. Advantages and Disadvantages of Oxygen Therapy Systems for Use at Home

\begin{tabular}{|c|c|c|}
\hline $\begin{array}{c}\text { Oxygen Delivery System: Stationary } \\
\text { and Portable/Backup }\end{array}$ & Advantages & Disadvantages \\
\hline Stationary concentrator with cylinders & $\begin{array}{l}\text { Provides continuous flow for home use and } \\
\text { ambulation } \\
\text { Cylinders can be used for backup oxygen } \\
\text { Usual maximum flow } 5 \mathrm{~L} ; 10 \mathrm{~L} \text { with larger devices } \\
\text { Cost } \\
\text { Ease of use } \\
\text { Simple operation }\end{array}$ & $\begin{array}{l}\text { Depending on flow, cylinders have limited } \\
\text { duration } \\
\text { Overnight trips are difficult; stationary } \\
\text { concentrator is heavy, and traveling with } \\
\text { excess cylinders is hazardous } \\
\text { Noise, power consumption } \\
\text { Required regular maintenance } \\
\text { Cannot be used on aircraft }\end{array}$ \\
\hline $\begin{array}{l}\text { Stationary concentrator with cylinders } \\
\text { and pulse dose regulator }\end{array}$ & $\begin{array}{l}\text { Provides continuous flow for home use and pulse } \\
\text { dose from cylinder for ambulation } \\
\text { Cylinders can be used for backup oxygen } \\
\text { Usual maximum flow } 5 \mathrm{~L} ; 10 \mathrm{~L} \text { with larger devices }\end{array}$ & $\begin{array}{l}\text { Overnight trips are difficult; stationary } \\
\text { concentrator is heavy, and traveling with } \\
\text { excess cylinders is hazardous } \\
\text { Weight of cylinders } \\
\text { Cannot be used on aircraft }\end{array}$ \\
\hline Portable oxygen concentrator & $\begin{array}{l}\text { Can be used for home stationary unit and for } \\
\text { ambulation } \\
\text { Typically includes a power cord allowing use in } \\
\text { automobile, allowing extended trips } \\
\text { Usual maximum flow pulse dose reported as } \\
\text { equivalent to } 6 \mathrm{~L} ; 0.5-3 \mathrm{~L} \text { of continuous flow } \\
\text { offered } \\
\text { Cost } \\
\text { Ease of use } \\
\text { Simple operation } \\
\text { Can be used on aircraft }\end{array}$ & $\begin{array}{l}\text { Limited battery duration } \\
\text { May not offer continuous flow } \\
\text { May not meet patient demands } \\
\text { Noise, power consumption } \\
\text { Required regular maintenance }\end{array}$ \\
\hline $\begin{array}{l}\text { Concentrator and compressor to fill } \\
\text { cylinders (with pulse dose } \\
\text { regulator) }\end{array}$ & $\begin{array}{l}\text { Provides continuous flow for home use and pulse } \\
\text { dose for ambulation } \\
\text { Cylinders can be used for backup } \\
\text { Patient can fill their own cylinders; no deliveries } \\
\text { required }\end{array}$ & $\begin{array}{l}\text { Overnight trips difficult; stationary } \\
\text { concentrator is heavy, and traveling with } \\
\text { excess cylinders is hazardous } \\
\text { Cannot be used on aircraft }\end{array}$ \\
\hline Liquid vessel and liquid portable & $\begin{array}{l}\text { Does not require electricity } \\
\text { Provides continuous flow for home use and pulse } \\
\text { dose for ambulation } \\
\text { Patient can fill their own portable; no deliveries } \\
\text { required } \\
\text { Can deliver high flow }\end{array}$ & $\begin{array}{l}\text { Overnight trips difficult; liquid vessel very } \\
\text { heavy and hazardous to transport, liquid } \\
\text { portable will not last overnight } \\
\text { Cost } \\
\text { Cannot be used on aircraft }\end{array}$ \\
\hline
\end{tabular}

scription that is explicit with respect to desired $\mathrm{S}_{\mathrm{pO}_{2}}$, with and without activity, should be the standard. Whether this is possible under the changing reimbursement system remains to be seen.

\section{Oxygen Source}

Based on reimbursement, logistics, and performance, there are a number of options for home oxygen delivery. In many cases, this includes a device for in home use, a portable device for mobility, and a backup system. ${ }^{70}$ These will be considered briefly below. Table 4 lists the advantages and disadvantages of home oxygen delivery devices.

\section{Cylinders}

Oxygen cylinders represent the original source of oxygen supply. Cylinders can provide continuous flow or be fitted with demand regulators to prolong duration of operation and efficacy. However, the short duration of operation, weight, handling, and logistics of replacing cylinders render this the least favorable option for home therapy. Small cylinders continue to be used for ambulation or as back-up systems in some situations. ${ }^{70}$

\section{Liquid}

Liquid oxygen systems provide a number of advantages compared with other devices. Liquid oxygen is more easily stored, transported, and transfilled than gaseous oxygen..$^{70}$ One $\mathrm{L}$ of liquid oxygen expands to $860 \mathrm{~L}$ of gaseous oxygen, allowing liquid systems a period of prolonged operation. Stationary liquid systems can be used to fill portable devices to enhance patient mobility. Liquid systems are also capable of high flows and are the best option for subjects with greater oxygen requirements. At present, the logistics and costs of 


\section{OXYGEN THERAPY IN COPD}

liquid systems have limited its adoption in home care. Portable liquid systems extend the time patients can be away from home but cannot be used for air travel.

\section{Concentrators}

Oxygen concentrators are the most common device used for home oxygen therapy. Devices can provide a wide range of oxygen flows (1-10L/min) at an oxygen purity of $90 \pm 5 \%$. When discussing oxygen concentrators, purity is essentially the $\mathrm{F}_{\mathrm{IO}_{2}}$ of the gas delivered to the patient. Concentrators are also capable of pulse-dose delivery to maximize efficacy and minimize power use. Current stationary concentrators weigh between 30 and 35 pounds and run more efficiently than previous devices. This includes lower power consumption, quieter operation, and reduced costs of ownership. ${ }^{70}$ Stationary concentrators typically allow a connecting tube up to 100 feet in length to allow the patient to be mobile within the home.

Certain portable concentrators allow filling of small cylinders to allow the patient to travel away from home. These devices have greater costs, and there are a number of logistics issues that must be overcome. Patient acceptance of this responsibility is important for successful use.

\section{Portable Oxygen Concentrators and the Meaning of Settings}

Portable oxygen concentrators (POCs) provide patients prolonged mobility outside the home through the use of batteries and operation from automobile power and other sources. Most POCs are also safe for air travel. POCs can provide continuous flow or pulse dose (also known as short-burst or intermittent flow). Depending primarily on size, POCs can provide a continuous flow of 0.5-3.0 L/min. ${ }^{70}$ This is an important distinction, as patients often prefer the smallest device, when oxygen production is the primary determinant of efficacy.

A common clinical conundrum with POC is the use of the pulse-dose mode. Most devices are labeled with dimensionless settings of $1-3$ or 1-6. Presumably, these values are equivalent to continuous-flow settings at these same values in $\mathrm{L} / \mathrm{min}$. This labeling is confusing for caregivers and patients alike. Again, the complicating factor is the patient's choice of a small, attractive, unobtrusive device that in all likelihood will not relieve hypoxemia during activity. The dose of oxygen during a 24-h period is important to achieve the therapeutic objective. The POC may fail in this goal if not chosen properly. ${ }^{70}$

A number of investigations have highlighted this problem. ${ }^{77-86}$ For a given maximum oxygen generation (in $\mathrm{L} / \mathrm{min}$ ), a POC can provide a pulse volume that is based on the patient's breathing frequency. For example, a device with a maximum oxygen-generating capacity of
$0.5 \mathrm{~L} / \mathrm{min}$ can deliver a volume of $25 \mathrm{~mL} / \mathrm{breath}$ at a frequency of 20 breaths/min at the desired oxygen purity. A device capable of generating $3 \mathrm{~L} / \mathrm{min}$ can provide a maximum pulse volume of $150 \mathrm{~mL} / \mathrm{breath}$ at a frequency of 20 breaths/min. In these 2 examples, the maximum setting (1-6) for each device provides drastically different oxygen delivery to the patient.

This issue is further complicated when respiratory frequency exceeds the oxygen-generating capacity of the POC. In this case, the operation of the POC must adopt one of 3 methods: (1) deliver a constant pulse volume at a reduced oxygen purity; (2) deliver a reduced pulse volume at a constant oxygen purity; (3) Deliver a constant pulse volume, responding only to every $2-3$ breaths.

These are clinically relevant differences that may result in drastically different oxygen saturations in active subjects. Choice of a POC should be a joint decision that includes patient desires for simplicity, cost, and weight along with testing to assure adequate patient oxygenation during use.

Jacobs et $\mathrm{al}^{87}$ have recently described patient perceptions related to home oxygen therapy. They analyzed almost 2,000 responses. The majority of respondents used oxygen $24 \mathrm{~h} / \mathrm{d}$ for $1-5 \mathrm{y}$, with $31 \%$ using high-flow oxygen with exertion. Only $29 \%$ of subjects adjusted oxygen flow based on oximeter readings. The majority $(65 \%)$ of subjects reported not having their $\mathrm{S}_{\mathrm{pO}_{2}}$ checked when equipment was delivered and set-up. Instruction at the time of delivery was provided by the delivery person $(64 \%)$ or clinician $(8 \%)$, or no instruction was given (10\%). A third of subjects reported feeling very or somewhat unprepared to operate their equipment. Half of respondents reported oxygen problems, most frequently reporting equipment malfunction, lack of physically manageable portable systems, and lack of portable systems with high flows. Limitations in activities outside the home due to inadequate portable oxygen systems was a common reported issue, occurring in $44 \%$ of subjects.

Importantly, subjects living in Competitive Bidding Program areas reported oxygen problems more often than those who did not. Those subjects reporting problems with their oxygen systems also experienced increased healthcare resource utilization. 87

I agree with previous discussions suggesting that POC should be labeled with the pulse volume at each setting to make the capabilities more transparent to patients and caregivers. ${ }^{70}$

\section{Closed-Loop Control of Oxygen at Home}

Several investigators have explored the use of closed-loop oxygen flow to overcome problems associated with varying 


\section{OXYGEN THERAPY IN COPD}
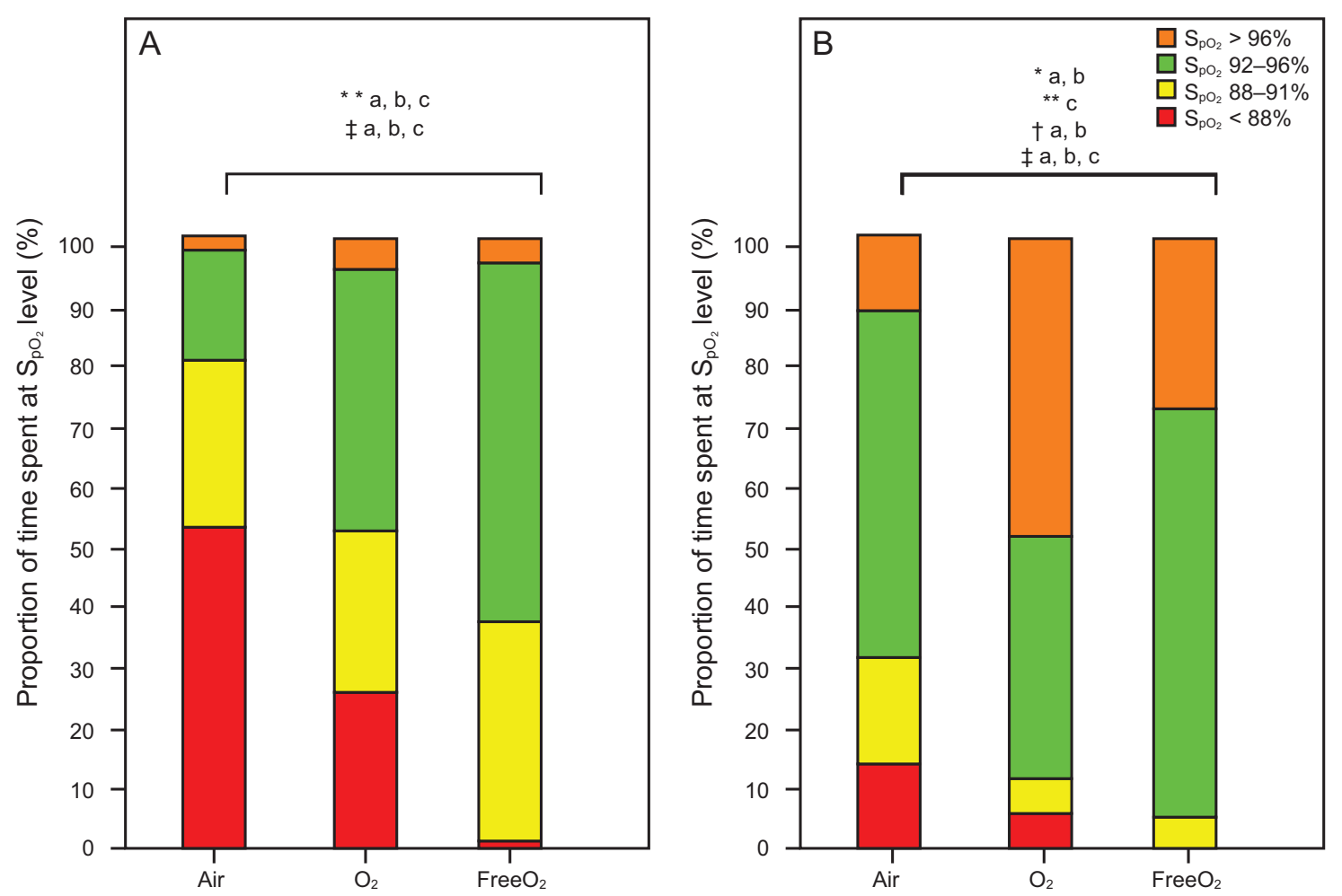

Fig. 3. Percentage of time spent within the predefined $\mathrm{S}_{\mathrm{pO}_{2}}$ ranges during the 3 tested conditions (compressed air, constant low-flow oxygen [ $\left.\mathrm{O}_{2}\right]$, and $\mathrm{FreeO}_{2}$ ), during the endurance shuttle walk test $(\mathrm{A})$ and during the 10-min recovery period $(\mathrm{B})$. The percentage of time within the oxygenation target $\left(\mathrm{S}_{\mathrm{pO}_{2}}=92-96 \%\right)$ was significantly higher with FreeO $\mathrm{O}_{2}$. The percentage of time with $\mathrm{S}_{\mathrm{pO}_{2}}<88 \%$ was significantly lower with FreeO . The percentage of time with hyperoxia $\left(\mathrm{S}_{\mathrm{pO}_{2}}>96 \%\right)$ was higher with constant oxygen flow. ${ }^{*} P<.05$ between groups for $\mathrm{S}_{\mathrm{pO}_{2}}>96 \%$; ${ }^{*} P<.05$ between groups for $\mathrm{S}_{\mathrm{pO}_{2}}$ 92-96\%; $\uparrow P<.05$ between groups for $\mathrm{S}_{\mathrm{pO}_{2}} 88-91 \%$; $¥ P<.05$ between groups for $\mathrm{S}_{\mathrm{pO}_{2}}<88 \%$; a $P<.05$ between air and $\mathrm{O}_{2}$; b $P<.05$ between air and $\mathrm{FreeO}_{2}$; c $P<.05$ between $\mathrm{O}_{2}$ and $\mathrm{FreeO}_{2}$. From Reference 91 .

patient demand during activity and changes in patient condition. ${ }^{88-92}$ These systems use pulse oximetry to control oxygen flow or pulse volume to maintain a desired $\mathrm{S}_{\mathrm{pO}_{2}}$. A least one system is FDA-cleared. ${ }^{88}$

Lellouche and colleagues ${ }^{91-94}$ have generated much of this work, using a system known as $\mathrm{FreeO}_{2}$. They demonstrated efficacy and greater duration of time in desired saturation ranges compared with traditional oxygen therapy during exercise, during COPD exacerbations, and in emergency care. Figure 3 demonstrates duration of time at $\mathrm{S}_{\mathrm{pO}_{2}}$ target between $\mathrm{FreeO}_{2}$ and conventional oxygen therapy during exercise (walking). ${ }^{91}$

These closed-loop systems are deceptively simple, and safety concerns related to excess oxygen delivery, monitoring respiratory frequency, and alerts to caregivers are important components. In fact, the use of an alert, letting caregivers know when oxygen requirements have increased, could be an underappreciated advantage of closed-loop oxygen flow. ${ }^{95}$ Unfortunately, the current cost pressures on home oxygen therapy and the new competitive bidding process may prevent this potentially valuable technology from reaching patients in the home.

\section{Oxygen Therapy and Noninvasive Ventilation}

The use of noninvasive ventilation (NIV) in chronic respiratory disease combined with oxygen therapy at home has recently been reported. ${ }^{96}$ Murphy et al ${ }^{96}$ report a randomized clinical trial of 116 subjects with hypercapnia in the United Kingdom allocated to receive either LTOT alone or LTOT plus NIV. Median oxygen flow was $1.0 \mathrm{~L} / \mathrm{min}$ in both groups, and median NIV settings were an inspiratory pressure of $24 \mathrm{~cm} \mathrm{H}_{2} \mathrm{O}$, PEEP of $4 \mathrm{~cm} \mathrm{H}_{2} \mathrm{O}$, and a set frequency of 14 breaths/min.

After 12 months, 64 subjects completed the 12-month trial. The median time to readmission or death was 4.3 months (interquartile range 1.3-13.8 months) in the LTOT plus NIV group versus 1.4 months (interquartile range $0.5-3.9$ months) in the LTOT alone group. The adjusted hazard ratio was 0.49 (95\% CI 0.31-0.77, $P=.002$ ). The 12-month risk of readmission or death was $63.4 \%$ in the LTOT plus NIV group versus $80.4 \%$ in the LTOT alone group. This demonstrated an absolute risk reduction of $17.0 \%$ (95\% CI $0.1-34.0 \%)$. At 12 months, 16 patients had died in the LTOT plus NIV group versus 19 in the LTOT alone group. They concluded that 


\section{OXYGEN THERAPY IN COPD}

Table 5. Recommendations Regarding Issues in Home Oxygen Therapy From the 2013 Respiratory CARE Journal Conference

Prescriptions and therapy for LTOT should focus on patient outcomes with oxygen saturations $>90 \%$ at all activity levels.

Prescriptions should allow for a titration to a specific saturation at all activity levels.

Labeling of the metering devices used with LTOT should include oxygen flow with a clinically acceptable $\mathrm{F}_{\mathrm{IO}_{2}}$ range.

Dose volume for intermittent-flow devices should be labeled based on calculated volume, in $\mathrm{mL}$, with the volume delivered in a breathing frequency range identified for $15-40$ breaths $/ \mathrm{min}$.

Oxygen purity monitoring should be available for all oxygen concentrator devices.

Alarms should initiate at concentrations $<85 \%$ purity for $>5 \mathrm{~min}$.

Portable concentrator alarms should initiate at breathing frequencies that produce oxygen purity $<85 \%$.

A new titration standard for oxygen prescriptions at all activity levels should be developed to ensure adequate patient oxygenation with the devices provided.

Appropriate and targeted reimbursement for RT professional service in the home is required to ensure that effective LTOT is provided.

Reimbursement for home oxygen equipment should reflect the cost of both products and services related to the effective delivery of the drug oxygen.

From Reference 70.

LTOT $=$ long-term oxygen therapy

$\mathrm{RT}=$ respiratory therapy

adding home NIV to home LTOT prolonged the time to readmission or death within 12 months. ${ }^{96}$

\section{Summary}

Oxygen therapy is a mainstay of treatment in COPD patients with resting hypoxemia. Other uses of LTOT for moderate hypoxemia, exercise-induced hypoxemia, nocturnal oxygen desaturation, and palliative care do not have strong evidence-based support. Despite these findings, oxygen is often delivered in these scenarios. Oxygen therapy during an exacerbation of COPD is potentially life-saving, but excessive oxygen is often delivered, to the detriment of survival. Current use of oxygen in pre-hospital and emergency care needs to match the knowledge regarding excess oxygen delivery from half a century ago. Closed-loop oxygen delivery might play a role in this arena. Devices for home oxygen delivery continue to face cost pressures, and reimbursement for professional respiratory care services is limited. A better appreciation of POC performance by caregivers and patients may lead to improved efficacy. A number of these issues have remained unchanged since the last RESPIRATORY CARE Journal Conference on oxygen therapy (Table 5).

\section{REFERENCES}

1. Croxton TL, Bailey WC. Long-term oxygen treatment in chronic obstructive pulmonary disease: recommendations for future research: an NHLBI workshop report. Am J Respir Crit Care Med 2006; 174(4):373-378.

2. Doherty DE, Petty TL, Bailey W, Carlin B, Cassaburi R, Christopher $\mathrm{K}$, et al. Recommendations of the 6th long-term oxygen therapy consensus conference. Respir Care 2006;51(5):519-525.

3. Nocturnal Oxygen Therapy Trial Group. Continuous or nocturnal oxygen therapy in hypoxemic chronic obstructive lung disease: a clinical trial. Ann Intern Med 1980;93(3):391-398.

4. Report of the Medical Research Council Working Party. Long term domiciliary oxygen therapy in chronic hypoxic cor pulmonale complicating chronic bronchitis and emphysema. Lancet 1981;1(8222): 681-686.

5. Long-Term Oxygen Treatment Trial Research Group, Albert RK, Au DH, Blackford AL, Casaburi R, Cooper JA Jr, et al. A randomized trial of long-term oxygen for COPD with moderate desaturation. N Engl J Med 2016;375(17):1617-1627.

6. O'Driscoll BR, Howard LS, Davison AG, British Thoracic Society. BTS Guideline for emergency oxygen use in adult patients. Thorax 2008;63(Suppl 6):vi1-68

7. Criner GJ. Ambulatory home oxygen: what is the evidence for benefit and who does it help? Respir Care 2013;58(1):48-64.

8. Heffner JE. The story of oxygen. Respir Care 2013;58(1):18-31.

9. Weitzenblum E, Sautegeau A, Ehrhart M, Mammosser M, Pelletier A. Long-term oxygen therapy can reverse the progression of pulmonary hypertension in patients with chronic obstructive pulmonary disease. Am Rev Respir Dis 1985;131(4):493-498.

10. Zieliński J, Tobiasz M, Hawrylkiewicz I, Sliwiński P, Pałasiewicz G. Effects of long-term oxygen therapy on pulmonary hemodynamics in COPD patients: a 6-year prospective study. Chest 1998;113(1):65-70.

11. Chaouat A, Weitzenblum E, Kessler R, Charpentier C, Enrhart M, Schott R, et al. A randomized trial of nocturnal oxygen therapy in chronic obstructive pulmonary disease patients. Eur Respir J 1999; 14(5):1002-1008

12. Górecka D, Gorzelak K, Sliwiński P, Tobiasz M, Zieliński J. Effect of long-term oxygen therapy on survival in patients with chronic obstructive pulmonary disease with moderate hypoxaemia. Thorax 1997;52(8):674-679.

13. Haidl P, Clement C, Wiese C, Dellweg D, Köhler D. Long-term oxygen therapy stops the natural decline of endurance in COPD patients with reversible hypercapnia. Respiration 2004;71(4):342-347.

14. Cranston JM, Crockett AJ, Moss JR, Alpers JH. Domiciliary oxygen for chronic obstructive pulmonary disease. Cochrane Database Syst Rev 2005;(4):CD001744.

15. Drummond MB, Blackford AL, Benditt JO, Make BJ, Sciurba FC, McCormack MC, et al. Continuous oxygen use in non-hypoxemic emphysema patients identifies a high-risk subset of patients: retrospective analysis of the National Emphysema Treatment Trial. Chest 2008;134(3):497-506.

16. Kim DK, Jacobson FL, Washko GR, Casaburi R, Make BJ, Crapo JD, et al. Clinical and radiographic correlates of hypoxemia and oxygen therapy in the COPDGene study. Respir Med 2011;105(8):1211-1221.

17. Hatipoğlu U, Stoller JK. Supplemental oxygen in patients with stable chronic obstructive pulmonary disease: evidence from Nocturnal Oxygen Treatment Trial to Long-term Oxygen Treatment Trial. Curr Opin Pulm Med 2018;24(2):179-186.

18. Ekström M. Clinical usefulness of long-term oxygen therapy in adults. N Engl J Med 2016;375(17):1683-1684.

19. Abernethy AP, McDonald CF, Frith PA, Clark K, Herndon JE 2nd, Marcello J, et al. Effect of palliative oxygen versus room air in relief of breathlessness in patients with refractory dyspnoea: a doubleblind, randomised controlled trial. Lancet 2010;376(9743):784-793.

20. Ekström M, Ringbaek T. Which patients with moderate hypoxemia benefit from long-term oxygen therapy? Ways forward. Int J Chron Obstruct Pulmon Dis 2018;13:231-235. 


\section{OXYGEN THERAPY IN COPD}

21. Ergan B, Nava S. Long-term oxygen therapy in COPD patients who do not meet the actual recommendations. COPD 2017;14(3):351-366.

22. Uronis HE, Ekström MP, Currow DC, McCrory DC, Samsa GP, Abernethy AP. Oxygen for relief of dyspnoea in people with chronic obstructive pulmonary disease who would not qualify for home oxygen: a systematic review and meta-analysis. Thorax 2015;70(5):492-494.

23. McDonald CF, Blyth CM, Lazarus MD, Marschner I, Barter CE. Exertional oxygen of limited benefit in patients with chronic obstructive pulmonary disease and mild hypoxemia. Am J Respir Crit Care Med 1995;152(5 Pt 1):1616-1619.

24. Eaton T, Garrett JE, Young P, Fergusson W, Kolbe J, Rudkin S, Whyte K. Ambulatory oxygen improves quality of life of COPD patients: a randomised controlled study. Eur Respir J 2002;20(2): 306-312.

25. Nonoyama ML, Brooks D, Guyatt GH, Goldstein RS. Effect of oxygen on health quality of life in patients with chronic obstructive pulmonary disease with transient exertional hypoxemia. Am J Respir Crit Care Med 2007;176(4):343-349.

26. Sandland CJ, Morgan MD, Singh SJ. Patterns of domestic activity and ambulatory oxygen usage in COPD. Chest 2008;134(4):753-760.

27. Davidson AC, Leach R, George RJ, Geddes DM. Supplemental oxygen and exercise ability in chronic obstructive airways disease. Thorax 1988;43(12):965-971.

28. Leggett RJ, Flenley DC. Portable oxygen and exercise tolerance in patients with chronic hypoxic cor pulmonale. Br Med J 1977;2(6079): 84-86.

29. Bradley BL, Garner AE, Billiu D, Mestas JM, Forman J. Oxygenassisted exercise in chronic obstructive lung disease: the effect on exercise capacity and arterial blood gas tensions. Am Rev Respir Dis 1978;118(2):239-243

30. Voduc N, Tessier C, Sabri E, Fergusson D, Lavallee L, Aaron SD. Effects of oxygen on exercise duration in chronic obstructive pulmonary disease patients before and after pulmonary rehabilitation. Can Respir J 2010;17(1):e14-e19.

31. Jolly EC, Di Boscio V, Aguirre L, Luna CM, Berensztein S, Gené RJ. Effects of supplemental oxygen during activity in patients with advanced COPD without severe resting hypoxemia. Chest 2001; 120(2):437-443

32. Emtner M, Porszasz J, Burns M, Somfay A, Casaburi R. Benefits of supplemental oxygen in exercise training in nonhypoxemic chronic obstructive pulmonary disease patients. Am J Respir Crit Care Med 2003;168(9):1034-1042.

33. Liker ES, Karnick A, Lerner L. Portable oxygen in chronic obstructive lung disease with hypoxemia and cor pulmonale: a controlled double-blind crossover study. Chest 1975;68(2):236-241.

34. Wadell K, Henriksson-Larsén K, Lundgren R. Physical training with and without oxygen in patients with chronic obstructive pulmonary disease and exercise-induced hypoxaemia. J Rehabil Med 2001;33(5): 200-205.

35. Rooyackers JM, Dekhuijzen PN, Van Herwaarden CL, Folgering HT. Training with supplemental oxygen in patients with COPD and hypoxaemia at peak exercise. Eur Respir J 1997;10(6):1278-1284.

36. Lewis CA, Fergusson W, Eaton T, Zeng I, Kolbe J. Isolated nocturnal oxygen desaturation in COPD: prevalence and impact of quality of life and sleep. Thorax 2009;64(2):133-138.

37. Lacasse Y, Sériès F, Vujovic-Zotovic N, Goldstein R, Bourbeau J, Lecours R, Aaron SD, Maltais F. Evaluating nocturnal oxygen desaturation in COPD—revised. Respir Med 2011;105(9):1331-1337.

38. Flick MR, Block AJ. Nocturnal vs diurnal cardiac arrhythmias in patients with chronic obstructive pulmonary disease. Chest 1979; 75(1):8-11.

39. Fletcher EC, Levin DC. Cardiopulmonary hemodynamics during sleep in subjects with chronic obstructive pulmonary disease: the effect of short and long-term oxygen. Chest 1984;85(1):6-14.
40. Calverley PM, Brezinova V, Douglas NJ, Catterall JR, Flenley DC. The effect of oxygenation on sleep quality in chronic bronchitis and emphysema. Am Rev Respir Dis 1982;126(2):206-210.

41. Fleetham J, West P, Mezon B, Conway W, Roth T, Kryger M. Sleep, arousals, and oxygen desaturation in chronic obstructive pulmonary disease. The effect of oxygen therapy. Am Rev Respir Dis 1982; 126(3):429-433.

42. Chaouat A, Weitzenblum E, Kessler R, Charpentier C, Ehrhart M, Levi-Valensi $\mathrm{P}$, et al. Sleep-related $\mathrm{O}_{2}$ desaturation and daytime pulmonary haemodynamics in COPD patients with mild hypoxaemia. Eur Respir J 1997;10(8):1730-1735.

43. Chaouat A, Weitzenblum E, Kessler R, Schott R, Charpentier C, Levi-Valensi $\mathrm{P}$, et al. Outcome of COPD patients with mild daytime hypoxaemia with or without sleep-related oxygen desaturation. Eur Respir J 2001;17(5):848-855.

44. Fletcher EC, Donner CF, Midgren B, Zielinski J, Levi-Valensi P, Braghiroli A, et al. Survival in COPD patients with a daytime $\mathrm{P}_{\mathrm{aO}_{2}}$ greater than $60 \mathrm{~mm} \mathrm{Hg}$ with and without nocturnal oxyhemoglobin desaturation. Chest 1992;101(3):649-655.

45. Fletcher EC, Luckett RA, Goodnight-White S, Miller CC, Qian W, Costarangos-Galarza C. A double-blind trial of nocturnal supplemental oxygen for sleep desaturation in patients with chronic obstructive pulmonary disease and a daytime $\mathrm{P}_{\mathrm{aO}_{2}}$ above $60 \mathrm{~mm} \mathrm{Hg}$. Am Rev Respir Dis 1992;145(5):1070-1076.

46. Lacasse Y, Bernard S, Sériès F, Nguyen VH, Bourbeau J, Aaron S, et al. Multicenter, randomized, placebo controlled trial of nocturnal oxygen therapy in chronic obstructive pulmonary disease: a study protocol for the INOX trial. BMC Pulm Med 2017;17(1):8.

47. Owens RL. Supplemental oxygen needs during sleep: who benefits? Respir Care 2013;58(1):32-47.

48. Campbell EJM. A method of controlled oxygen administration which reduces the risk of carbon dioxide retention. Lancet 1960;2(7140): 12-14.

49. Milic-Emili J, Aubier M. Some recent advances in the study of the control of breathing in patients with chronic obstructive lung disease. Anesth Analg 1980;59(11):865-873.

50. Aubier M, Murciano D, Fournier M, Milic-Emili J, Pariente R, Derenne JP. Central respiratory drive in acute respiratory failure of patients with chronic obstructive pulmonary disease. Am Rev Respir Dis 1980;122(2):191-199.

51. Aubier M, Murciano D, Milic-Emili J, Touaty E, Daghfous J, Pariente R, Derenne JP. Effects of the administration of $\mathrm{O}_{2}$ on ventilation and blood gases in patients with chronic obstructive pulmonary disease during acute respiratory failure. Am Rev Respir Dis 1980; 122(5):747-754.

52. Durrington HJ, Flubacher M, Ramsay CF, Howard LS, Harrison BD. Initial oxygen management in patients with an exacerbation of chronic obstructive pulmonary disease. QJM 2005;98(7):499-504.

53. Branson RD, Johannigman JA. Oxygen in prehospital care. Respir Care 2013;58(1):86-97.

54. Cameron L, Pilcher J, Weatherall M, Beasley R, Perrin K. The risk of serious adverse outcomes associated with hypoxaemia and hyperoxaemia in acute exacerbations of COPD. Postgrad Med J 2012; 88(1046):684-689.

55. Austin MA, Wills KE, Blizzard L, Walters EH, Wood-Baker R. Effect of high flow oxygen on mortality in chronic obstructive pulmonary disease patients in prehospital setting: randomised controlled trial. BMJ 2010;341:c5462.

56. Wijesinghe M, Perrin K, Healy B, Hart K, Clay J, Weatherall M, Beasley R. Pre-hospital oxygen therapy in acute exacerbations of chronic obstructive pulmonary disease. Intern Med J 2011;41(8): 618-622. 


\section{OXYGEN THERAPY IN COPD}

57. O'Driscoll BR, Howard LS, Davison AG, British Thoracic Society. Emergency oxygen use in adult patients: concise guidance. Clin Med 2011;11(4):372-375.

58. O'Driscoll BR. Safe use of emergency oxygen in chronic respiratory disease. Chron Respir Dis 2011;8(3):159-161.

59. Burring L, Smith JE. Use of emergency oxygen in adult patients: implementing change. Emerg Med J 2011;28(3):249-250.

60. Ek K, Andershed B, Sahlberg-Blom E, Ternestedt BM. "The unpredictable death": the last year of life for patients with advanced COPD: relatives' stories. Palliat Support Care 2015;13(5):1213-1222.

61. Ahmadi Z, Lundström S, Janson C, Strang P, Emtner M, Currow DC, Ekström M, et al. End-of-life care in oxygen-dependent COPD and cancer: a national population-based study. Eur Respir J 2015; 46(4):1190-1193.

62. Carlucci A, Guerrieri A, Nava S. Palliative care in COPD patients: is it only an end-of-life issue? Eur Respir Rev 2012;21(126):347354.

63. Hardinge M, Annandale J, Bourne S, Cooper B, Evans A, Freeman $\mathrm{D}$, et al. British Thoracic Society guidelines for home oxygen use in adults. Thorax 2015;70(Suppl 1):i1-i43.

64. Booth S, Wade R, Johnson M, Kite S, Swannick M, Anderson H, Expert Working Group of the Scientific Committee of the Association of Palliative Medicine. The use of oxygen in the palliation of breathlessness: a report of the expert working group of the Scientific Committee of the Association of Palliative Medicine. Respir Med 2004;98(1):66-77.

65. Campbell ML, Yarandi H, Dove-Medows E. Oxygen is non-beneficial for most patients who are near death. J Pain Symptom Manage 2013;45(3):517-523.

66. O'Donnell DE, Banzett RB, Carrieri-Kohlman V, Casaburi R, Davenport PW, et al. Pathophysiology of dyspnea in chronicobstructive pulmonary disease: a roundtable. Proc Am Thorac Soc 2007;4(2): $145-68$.

67. Davidson PM, Johnson MJ. Update on the role of palliative oxygen. Curr Opin Support Palliat Care 2011;5(2):87-91.

68. Nishimura M. High-flow nasal cannula oxygen therapy in adults: physiological benefits, indication, clinical benefits, and adverse effects. Respir Care 2016;61(4):529-541.

69. Nagata K, Kikuchi T, Horie T, Shiraki A, Kitajima T, et al. Domiciliary high-flow nasal cannula oxygen therapy for patients with stable hypercapnic chronic obstructive pulmonary disease: a multicenter randomized crossover trial. Ann Am Thorac Soc 2018(4):432439.

70. McCoy R. Options for home oxygen therapy equipment: storage and metering of oxygen in the home. Respir Care 2013;58(1):65-85.

71. Centers for Medicare and Medicaid Services, Medicare Learning Network. Home Oxygen Therapy. https://www.cms.gov/Outreachand-Education/Medicare-Learning-Network-MLN/MLNProducts/ Downloads/Home-Oxygen-Therapy-Text-Only.pdf. Accessed April 18, 2018.

72. Díaz Lobato S, García González JL, Mayoralas Alises S. The debate on continuous home oxygen therapy. Arch Bronconeumol 2015; 51(1):31-37

73. Serginson JG, Yang IA, Armstrong JG, Cooper DM, Matthiesson AM, Morrison SC, Gair JM, Cooper B, Zimmerman PV. Variability in the rate of prescription and cost of domiciliary oxygen therapy in Australia. Med J Aust 200916;191(10):549-553.

74. O’Neill B, Bradley JM, McKevitt AM, Heaney L, Riley M, McGovern V, MacMahon J. Prescribing practice for intermittent oxygen therapy: a GP survey. Chron Respir Dis 2004;1(3):139-142.

75. Hungin AP, Chinn DJ, Convery B, Dean C, Cornford CS, Russell A. The prescribing and follow-up of domiciliary oxygen-whose responsibility? A survey of prescribing from primary care. Br J Gen Pract 2003;53(494):714-715
76. Chaney JC, Jones K, Grathwohl K, Olivier KN. Implementation of an oxygen therapy clinic to manage users of long-term oxygen therapy. Chest 2002;122(5):1661-1667.

77. Khor YH, McDonald CF, Hazard A, Symons K, Westall G, Glaspole I, et al. Portable oxygen concentrators versus oxygen cylinder during walking in interstitial lung disease: a randomized crossover trial. Respirology 2017;22(8):1598-1603.

78. Chen JZ, Katz IM, Pichelin M, Zhu K, Caillibotte G, Noga ML, et al. Comparison of pulsed versus continuous oxygen delivery using realistic adult nasal airway replicas. Int J Chron Obstruct Pulmon Dis 2017;12:2559-2571.

79. Yáñez AM, Prat JP, Álvarez-Sala JL, Calle M, Díaz Lobato S, et al Oxygenation with a single portable pulse-dose oxygen-conserving device and combined stationary and portable oxygen delivery devices in subjects with COPD. Respir Care 2015;60(3):382-387.

80. Zhou S, Chatburn RL. Effect of the anatomic reservoir on low-flow oxygen delivery via nasal cannula: constant flow versus pulse flow with portable oxygen concentrator. Respir Care 2014;59(8):1199-1209.

81. O'Reilly Nugent A, Kelly PT, Stanton J, Swanney MP, Graham B, Beckert L. Measurement of oxygen concentration delivered via nasal cannulae by tracheal sampling. Respirology 2014;19(4):538-543.

82. Leblanc CJ, Lavallée LG, King JA, Taylor-Sussex RE, Woolnough A, McKim DA. A comparative study of 3 portable oxygen concentrators during a 6-minute walk test in patients with chronic lung disease. Respir Care 2013;58(10):1598-1605.

83. Martí S, Pajares V, Morante F, Ramón MA, Lara J, Ferrer J, Güell MR. Are oxygen-conserving devices effective for correcting exercise hypoxemia? Respir Care 2013;58(10):1606-1613.

84. Chatburn RL, Williams TJ. Performance comparison of 4 portable oxygen concentrators. Respir Care 2010;55(4):433-442. Erratum in: Respir Care 2010 Jun;55(6):789.

85. Nasilowski J, Przybylowski T, Zielinski J, Chazan R. Comparing supplementary oxygen benefits from a portable oxygen concentrator and a liquid oxygen portable device during a walk test in COPD patients on long-term oxygen therapy. Respir Med 2008;102(7):1021-1025.

86. Bliss PL, McCoy RW, Adams AB. Characteristics of demand oxygen delivery systems: maximum output and setting recommendations. Respir Care 2004;49(2):160-165.

87. Jacobs SS, Lindell KO, Collins EG, Garvey CM, Hernandez C, McLaughlin S, et al. Patient perceptions of the adequacy of supplemental oxygen therapy: results of the American Thoracic Society Nursing Assembly Oxygen Working Group Survey. Ann Am Thorac Soc 2018;15(1):24-32.

88. Cirio S, Nava S. Pilot study of a new device to titrate oxygen flow in hypoxic patients on long term oxygen therapy. Respir Care 2011; 56(4):429-434

89. Rice KL, Schmidt MF Buan JS, Lebahn F, Schwarzock TK. AccuO2 oximetry driven oxygen conserving device versus fixed dose oxygen devices in stable COPD patients. Respir Care 2011;56(12):19011905.

90. Lellouche F, Lipes J, L'Her E. Optimal oxygen titration in patients with chronic obstructive pulmonary disease: a role for automated oxygen delivery? Can Respir J 2013;20(4):259-261.

91. Lellouche F, L'Her E, Bouchard PA, Brouillard C, Maltais F. Automatic oxygen titration during walking in subjects with COPD: a randomized crossover controlled study. Respir Care 2016;61(11): 1456-1464.

92. Lellouche F, Bouchard PA, Roberge M, Simard S, L'Her E, Maltais F, Lacasse Y. Automated oxygen titration and weaning with $\mathrm{FreeO}_{2}$ in patients with acute exacerbation of COPD: a pilot randomized trial. Int J Chron Obstruct Pulmon Dis 2016;11:1983-1990.

93. L'Her E, Dias P, Gouillou M, Riou A, Souquiere L, Paleiron N, et al. Automatic versus manual oxygen administration in the emergency department. Eur Respir J 2017;50(1):1602552. 


\section{OXYGEN THERAPY IN COPD}

94. Poder TG, Kouakou CRC, Bouchard PA, Tremblay V, Blais S, Maltais F, Lellouche F. Cost-effectiveness of $\mathrm{FreeO}_{2}$ in patients with chronic obstructive pulmonary disease hospitalised for acute exacerbations: analysis of a pilot study in Quebec. BMJ Open 2018;8(1):e018835.

95. Liu NT, Salter MG, Khan MN, Branson RD, Enkhbaatar P, Kramer GC, Salinas J, Marques NR, Kinsky MP. Closed-loop control of $\mathrm{F}_{\mathrm{IO}_{2}}$ rapidly identifies need for rescue ventilation and reduces ARDS severity in a conscious sheep model of burn and smoke inhalation injury. Shock 2017;47(2):200-207.

96. Murphy PB, Rehal S, Arbane G, Bourke S, Calverley PMA, Crook $\mathrm{AM}$, et al. Effect of home noninvasive ventilation with oxygen therapy vs oxygen therapy alone on hospital readmission or death after an acute COPD exacerbation: a randomized clinical trial. JAMA 2017;317(21):2177-2186.

\section{Discussion}

Williams: I was really intrigued by an earlier comment you made about the coronary vasoconstrictor effect, and I'd be interested in your opinion. Of course, I think we know that $\mathrm{O}_{2}$ is a vasodilator in pulmonary hypoxic conditions. So one of the situations in which you didn't talk about the use of $\mathrm{O}_{2}$ and my experience and interest is this rationale for the patient with an asthma attack who has increased work of breathing but still has adequate $\mathrm{O}_{2}$ saturation but is going to get aggressive $\beta$-agonist therapy and may have this paradoxical hypoxemia. Is that a situation where it's reasonable to supplement $\mathrm{O}_{2}$ ?

Branson: The data on $\mathrm{O}_{2}$ therapy and asthma are virtually nonexistent. If you have asthma and you need $\mathrm{O}_{2}$, that is a real poor predictor of how well you're doing. Conventional wisdom suggests that if you're going to give an updraft nebulizer for their asthma, that you should power it with $\mathrm{O}_{2}$. There is a study looking at the impact of oxygenation in subjects with asthma showing the same rise in $\mathrm{P}_{\mathrm{CO}_{2}}$ and fall in $\mathrm{pH}$, almost what you see in COPD. It's not as severe, but again that's changing ventilation perfusion, because you're filling the alveoli that have low ventilation with $\mathrm{O}_{2}$ and allowing them to collapse.

*Hess: Neil [MacIntyre], I'm going to turn the tables and ask you a question that you would probably ask me if our roles were reversed. You and Bob [Wise] were coauthors on the LOTT study. ${ }^{2}$ When do you prescribe $\mathrm{O}_{2}$ for patients with COPD with mild hypoxemia or who desaturate during exercise or at night?

MacIntyre: I think Bob would love to answer that one.

Wise: This has caused a huge uproar in the community.

*Hess: Which is why I asked the question.

Wise: Yes, thank you. Sam [Giordano], maybe you can respond - Sam has been at the center of this vortex. Perhaps you can at least explain what the uproar has been.

Giordano: I'll be glad to. I'm speaking in my role as chair of the United States COPD Coalition, which is a patient advocacy group consisting of state coalitions. There indeed is a lot of concern in the patient community. They're afraid that CMS [Centers for Medicare and Medicaid Services] will use the results of this study to raise the threshold requirement for reimbursement of supplemental oxygen. The Coalition invited Bob to provide a briefing at one of our member webinars on the study a few months ago. He did a wonderful job of putting the results in perspective and offering reassurance to patients and providers. I think that the salient takeaway from the study - and it seems like patients seem to get it - is what you told me on the telephone several months ago, Bob. The results do not mean they will not get $\mathrm{O}_{2}$ if they get some symptom relief. But, and again as Bob pointed out, there are certain patients who may be on $\mathrm{O}_{2}$ who fall into the moderately hypoxemic category who don't want to be on supplemental oxygen, and de- rive no symptom relief. This study indicates that there isn't a medical reason for them to continue.

MacIntyre: I'll chime in and generally agree with everyone here. There are data, and Rich reviewed them, on the hypoxemic subject with exercise who gets on $\mathrm{O}_{2}$. Not in all studies, but in general, increase their 6-min walk test distance, and they get functional benefit from it. I think that's real. There are other studies that show that it will reduce pulmonary artery pressure, and that seems to be real. What the current studies show is that those physiologic changes don't necessarily spill over into mortality or exacerbation benefits. Nevertheless, these intermediate values of increased exercise tolerance, reduced symptoms, and the like are legit, and from every indication I get, CMS is not interested in going after those indications. I think the chances of the rules changing, at least in the foreseeable future, are pretty low.

Giordano: Exactly on point. We spoke with CMS regarding this concern. They were involved in discussions we had with the Coalition and the community. They were emphatic that they're not going to change reimbursement policy based on one study. I would like to transition to CMS reimbursement policy for $\mathrm{O}_{2}$, which is something Rich threw out to the group during his presentation. For the first time in over 30 years, I think CMS is aware of the mistake we made by trying to commoditize $\mathrm{O}_{2}$. There are far too many technical nuances associated with supplemental oxygen systems to make this approach work for patients. Because 
it's treated like a commodity, you can buy a case of Depends with bidding but you can't really bid on $\mathrm{O}_{2}$ and still offer a full range of delivery systems without the potential for underserving patient needs. Rich showed us several pictures of $\mathrm{O}_{2}$ concentrators, and the long and the short of it is if a concentrator is not continuous-flow-capable, its output cannot be equated to $\mathrm{L}$ flow. On the other hand if the device is capable of continuous flow, weight and battery life are factors. Even when set in pulse-dose mode it's going to have an equivalency in $\mathrm{L} / \mathrm{min}$. Devices incapable of continuous flow output do not have their outputs calibrated in $\mathrm{L} / \mathrm{min}$. This variance in performance is confusing to patients and physicians alike. The Internet offers so many benefits, but in this case, perhaps not. It seems patients get online and contact manufacturers directly. They are told by some sales people that their device will meet their needs but then discover the opposite in some cases. I am beginning to think that CMS does understand, now, that it may be time to change the way we prescribe $\mathrm{O}_{2}$. I started as an inhalation therapist a couple of years before Medicare was passed and implemented. I was just on the tail of $\mathrm{O}_{2}$ tents and iron lungs. So, I remember the oxygen prescription was to maintain a target $\mathrm{O}_{2}$ concentration inside of a tent. When we finally made the complete switch to catheters, cannulas, and masks, then it was prescribed as a device output in $\mathrm{L} / \mathrm{min}$. At the time, we never anticipated having all of these different delivery devices with a wide variety of technical capabilities. The biggest common denominator, with regard to the $\mathrm{O}_{2}$ prescription should be targeting a pulse oximeter saturation range. This change would allow physicians to prescribe a target saturation range as a substitute for $\mathrm{L} / \mathrm{min}$, while recognizing the technological advances in terms of delivery systems. Better yet, have a respiratory therapist or a nurse who has delved into this technology, as several have, or a physical therapist or others to provide advice regarding the right piece of equipment for each patient. However, the certificate of medical necessity form (CMN484) makes no provision for a prescription unless it's in $\mathrm{L} / \mathrm{min}$. Something came out of CMS about 3 or 4 months ago that indicated that their documentation for the order Rich had mentioned some from the United Kingdom - but with CMS slightly over $48 \%$ of the certificates for medical necessity for home $\mathrm{O}_{2}$ were incomplete. We're not even getting the proper order. They know about changing the form; we hope they will do that.

$\dagger$ Newhouse: I'm amazed that we're still debating controlled $\mathrm{O}_{2}$. Campbell demonstrated very clearly in the late 50 s that it was essential not to go above $40 \%$, and he developed the airentrainment mask. And here we are 60 years later still debating what was demonstrated very clearly then. ${ }^{3}$

\section{REFERENCES}

1. Perrin K, Wijesinghe M, Healy B, Wadsworth K, Bowditch R, Bibby S, et al. Randomised controlled trial of high concentration versus titrated oxygen therapy in severe exacerbations of asthma. Thorax 2011; 66(11):937-941

2. The Long-Term Oxygen Treatment Trial Research Group, Albert RK, Au DH, Blackford AL, Casaburi R, Cooper JA Jr. A randomized trial of long-term oxygen for COPD with moderate desaturation. N Eng1 J Med 2016;375(17):1617-1627.

3. Campbell EJM. A method of controlled oxygen administration which reduces the risk of carbon dioxide retention. Lancet 1960; 2(7140):12-14.

* Dean R Hess PhD RRT FAARC, discussant. Dr Hess is Managing Editor of ResPIRATORY CARE.

$\dagger$ Michael T Newhouse MD, invited discussant. Dr Newhouse is the chief medical officer for InspiRx. 